\title{
Miniaturized MIMO Antenna with Low Inter-radiator Transmittance and Band Rejection Features
}

\author{
Muhammad Irshad Khan ${ }^{1, *} \cdot$ Muhammad Irfan Khattak ${ }^{1} \cdot$ Mauth A1-Hasan $^{2}$
}

\begin{abstract}
In this article, compact a multiple-input and multiple-output (MIMO) system with flag-shaped radiators and a mountain-shaped ground plane is presented. Isolation is enhanced with the help of a decoupling stub placed between radiators, where two bands are stopped with the help of slits etched into the radiators. The overall size of the proposed antenna is $15 \mathrm{~mm} \times 25 \mathrm{~mm} \times 1.6 \mathrm{~mm}$. The reflection coefficients are less than $-10 \mathrm{~dB}$ between 3-10.9 GHz, except the bands WiMAX (3.2-3.7 GHz) and WLAN (5-6 GHz); similarly, measured and simulated transmission coefficients are less than $-20 \mathrm{~dB}$ across the entire band of UWB. The envelope correlation coefficient (ECC) is less than 0.02 and the diversity gain is greater than $9.9 \mathrm{~dB}$. The gain, ECC, radiation pattern, multiplexing efficiency, diversity gain and various other parameters are discussed and evaluated in detail.
\end{abstract}

Key Words: Envelope Correlation Coefficient, Gain, Impedance Bandwidth, MIMO, UWB.

\section{INTRODUCTION}

The Federal Communications Commission (FCC) has for the first time authorized ultra-wideband (UWB) range from 3.1 to $10.6 \mathrm{GHz}$ in 2002 [1]. UWB requires very low transmittance power, achieves very high data rates and is not in a line of sight. Despite various advantages, UWB also have drawbacks like interference with existing narrow bands and multipath fading. Various techniques have been used to overcome interference problems [2-5], and multiple-input and multiple-output (MIMO) antennas have been used on both transmitting and receiving sides to reduce multipath fading [6-9]. The intent of the present research work is to study miniaturized MIMO antennas with decoupling stubs for low transmission coefficients and etched slits in radiating patches for stop-band features.

Various techniques have been used to reduce mutual coupling, such as decupling stubs, electromagnetic band gaps (EBG), split ring resonators, LC resonance, and suspended lines [10-25]. The author designed a MIMO antenna with decoupling stub for isolation, where isolation is $15 \mathrm{~dB}$ and $\mathrm{ECC}$ is less than 0.08; the dimension of the antenna is $26 \mathrm{~mm} \times 28 \mathrm{~mm} \times 0.8 \mathrm{~mm}$ [10]. In the study by Liu et al. [11], the authors designed a singlenotched band MIMO antenna with decoupling stub for mutual coupling reduction, where the dimension of the antenna was 22 $\mathrm{mm} \times 36 \mathrm{~mm}$, the envelope correlation coefficient (ECC) was less than 0.1 and the transmission coefficient was less than -15 dB. A circular-shaped MIMO antenna with dual-stopped bands of WiMAX and WLAN was presented, where the dimension of the antenna was $35 \mathrm{~mm} \times 68 \mathrm{~mm}$; a simple decoupling stub was used to reduce mutual coupling [12]. Jaglan et al. [13] designed a circular-shaped MIMO antenna with EBG for dual-stop bands and decoupling strips for isolation; the dimension of the antenna

Manuscript received October 18, 2020 ; Revised December 27, 2020 ; Accepted April 8, 2021. (ID No. 20201018-168J)

${ }^{1}$ Department of Electrical Engineering, University of Engineering and Technology, Peshawar, Pakistan.

${ }^{2}$ College of Engineering, Al-Ain University, UAE.

"Corresponding Author: Muhammad Irshad Khan (e-mail: m.i.khan@uetpeshawar.edu.pk)

This is an Open-Access article distributed under the terms of the Creative Commons Attribution Non-Commercial License (http://creativecommons.org/licenses/by-nc/4.0) which permits unrestricted non-commercial use, distribution, and reproduction in any medium, provided the original work is properly cited.

(c) Copyright The Korean Institute of Electromagnetic Engineering and Science. 
was $64 \mathrm{~mm} \times 45 \mathrm{~mm} \times 1.6 \mathrm{~mm}$. Haq and Koziel [14] designed a MIMO antenna with decoupling stub, where the transmission coefficient was less than $-20 \mathrm{~dB}$ and the ECC was less than 0.005; the dimension of the antenna was $25 \mathrm{~mm}$ $\times 32 \mathrm{~mm}$.

Li et al. [15] presented a Vivaldi MIMO antenna with dualstopped bands, where the size of the antenna was $26 \mathrm{~mm} \times 26$ $\mathrm{mm}$, the isolation was greater than $16 \mathrm{~dB}$ and the ECC was less than 0.02 [15]. Kumar et al. [16] designed an octagonal-shaped MIMO antenna with dual-stop bands; the dimension of the antenna was $19 \mathrm{~mm} \times 30 \mathrm{~mm} \times 0.8 \mathrm{~mm}$, isolation was greater than $18 \mathrm{~dB}$ and the ECC was less than 0.13 [16]. Chattha et al. [17] designed a MIMO antenna with a dimension of $23 \mathrm{~mm} \times$ $26 \mathrm{~mm} \times 0.8 \mathrm{~mm}$ with a single-stopped band of WLAN; the isolation was greater than $20 \mathrm{~dB}$ and the ECC was less than 0.06. In the study by Babu and Anuradha [18], the authors designed a large rectangular antenna with the dimensions $60 \mathrm{~mm}$ $\times 35 \mathrm{~mm}$, a transmission coefficient less than $-16.53 \mathrm{~dB}$ and an ECC less than 0.04. In [19], the authors designed a large dualnotched band MIMO antenna with the dimensions $40 \mathrm{~mm} \times$ $20 \mathrm{~mm}$ and isolation greater than $15 \mathrm{~dB}$. In [20], the authors designed a circular-shaped MIMO antenna with EBG structure for isolation, where the overall dimension of the antenna was $27.2 \mathrm{~mm} \times 46 \mathrm{~mm}$, the isolation was greater than $18 \mathrm{~dB}$ and the ECC was less than 0.018. In the study by Khan and Khattak [21], the authors proposed a MIMO antenna with a T-shaped decoupling stub and dual-stop band of WiMAX and WLAN; the dimension of the antenna was $18 \mathrm{~mm} \times 36 \mathrm{~mm}$, the isolation was greater than $20 \mathrm{~dB}$ and the ECC was less than 0.05 . Overall, the above designs are large in size, have low isolation and add additional complexity to the antenna structures. A detailed comparison among the proposed designs within the existing literature is shown in Table 1.

In the current paper, a dual-notched band MIMO antenna that is compact in size is presented, where the decoupling stub is used to achieve a low transmission coefficient. The overall size of antenna is $15 \mathrm{~mm} \times 25 \mathrm{~mm} \times 1.6 \mathrm{~mm}$. Two slits are etched in the radiating patch to stop the bands of WiMAX and WLAN. The proposed antenna has high isolation, compact size and good diversity performance compared with the designs in the cited literature.

\section{ANTENNA DESIGN CONFIGURATION}

\section{Antenna Design}

The proposed antenna is printed on low cost FR4 dielectric substrate with a height of $1.6 \mathrm{~mm}$, relative permittivity of 4.4 and loss tangent of 0.02 . The proposed design consists of two similarly structured radiating patches, a mountain-shaped ground plane and a T-shape decoupling stub. The overall dimensions of the
Table 1. Comparison among proposed designs with literature cited

\begin{tabular}{|c|c|c|c|c|}
\hline Study & $\begin{array}{l}\text { Size } \\
(\mathrm{mm})\end{array}$ & $\begin{array}{l}\text { Isolation } \\
(\mathrm{dB})\end{array}$ & $\mathrm{ECC}$ & $\begin{array}{l}\text { Diversity } \\
\text { gain }(\mathrm{dB})\end{array}$ \\
\hline Zhao et al. [10] & $26 \times 28$ & $>15$ & $<0.08$ & $>9.5$ \\
\hline Liu et al. [11] & $22 \times 36$ & $>15$ & $<0.1$ & - \\
\hline Li et al. [12] & $35 \times 68$ & $>20$ & $<0.035$ & - \\
\hline Jaglan et al. [13] & $64 \times 45$ & $>15$ & $<0.02$ & - \\
\hline Haq and Koziel [14] & $25 \times 32$ & $>20$ & $<0.005$ & $>9.9$ \\
\hline Li et al. [15] & $26 \times 26$ & $>16$ & $<0.02$ & - \\
\hline Kumar et al. [16] & $19 \times 30$ & $>18$ & $<0.13$ & - \\
\hline Chattha et al. [17] & $23 \times 26$ & $>20$ & $<0.06$ & - \\
\hline $\begin{array}{l}\text { Babu and } \\
\text { Anuradha [18] }\end{array}$ & $60 \times 35$ & $>16.53$ & $<0.04$ & 9.99 \\
\hline Mathur and Dwari [19] & $40 \times 20$ & $>15$ & $<0.30$ & - \\
\hline Dabas et al. [20] & $27.2 \times 46$ & $>18$ & $<0.018$ & $>9.9$ \\
\hline Khan and Khattak [21] & $18 \times 36$ & $>20$ & $<0.05$ & $>9.8$ \\
\hline Lee et al. [22] & $90 \times 50$ & $>15$ & $<0.08$ & - \\
\hline Lim et al. [23] & $70 \times 48$ & $>15$ & $<0.08$ & - \\
\hline Kumar et al. [26] & $36 \times 36$ & $>18$ & $<0.06$ & $>9.95$ \\
\hline Biswal and Das [27] & $30 \times 30$ & $>20$ & $<0.013$ & $>9.51$ \\
\hline Kang et al. [28] & $38.5 \times 38.5$ & $>15$ & $<0.02$ & - \\
\hline Rajkumar et al. [29] & $40 \times 40$ & $>20$ & $<0.04$ & - \\
\hline Proposed & $15 \times 25$ & $>20$ & $<0.02$ & $>9.9$ \\
\hline
\end{tabular}

proposed design are $15 \mathrm{~mm} \times 25 \mathrm{~mm} \times 1.6 \mathrm{~mm}$. The top and bottom views of the designed MIMO antenna are depicted in Fig. 1 and their $|S|$-parameters are illustrated in Fig. 2.

The width of the radiating patch $\left(w_{r}\right)$ is $7.7 \mathrm{~mm}$, the outer and inner lengths of the radiating patch are $9.5 \mathrm{~mm}$ and 3.5 $\mathrm{mm}$, denoted respectively by $l_{4}$ and $l_{1}$. The space between the two radiating elements is $9.6 \mathrm{~mm}$. The length and width of the feed line are $7.5 \mathrm{~mm}$ and $1.4 \mathrm{~mm}$, respectively. The ground plane consists of two half-circular discs and decoupling stubs. The radius of the half circular disc is $6 \mathrm{~mm}$, and the length and width of the decoupling stub are $15 \mathrm{~mm}$ and $3 \mathrm{~mm}$, respectively. Various other design parameters are summarized in Table 2.

\section{Decoupling Stub}

Mutual coupling is a basic problem in MIMO antenna systems. The deployment of multiple antennas across small dis- 


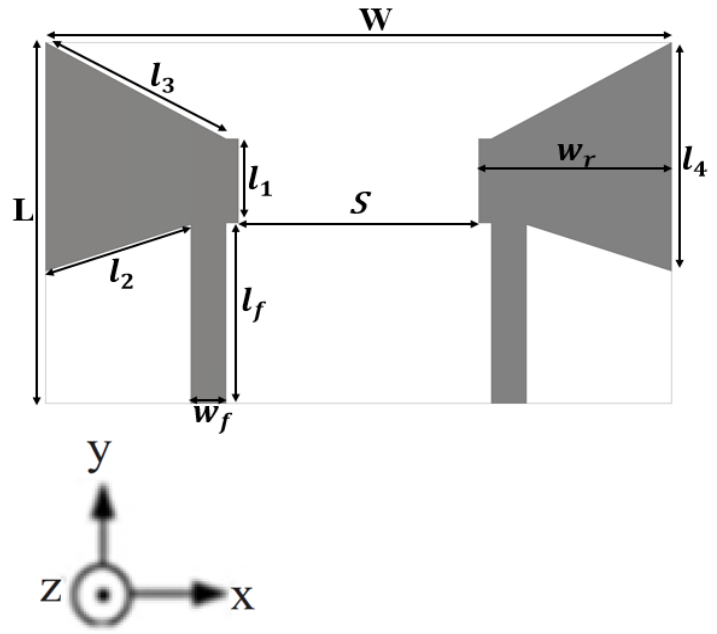

(a)

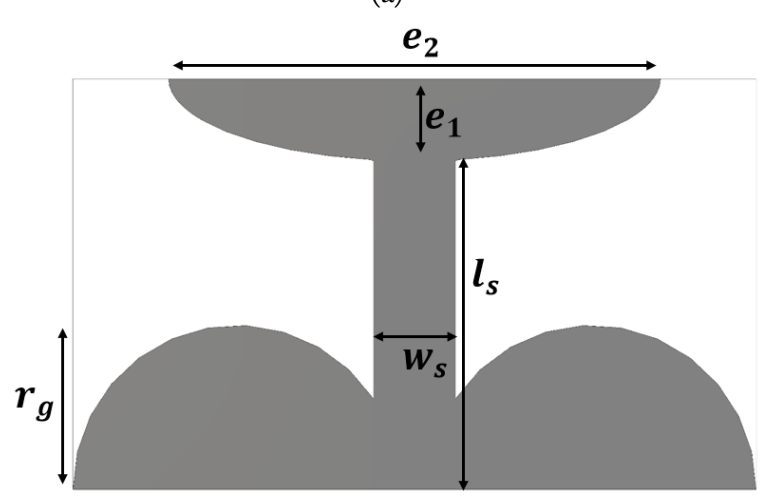

(b)

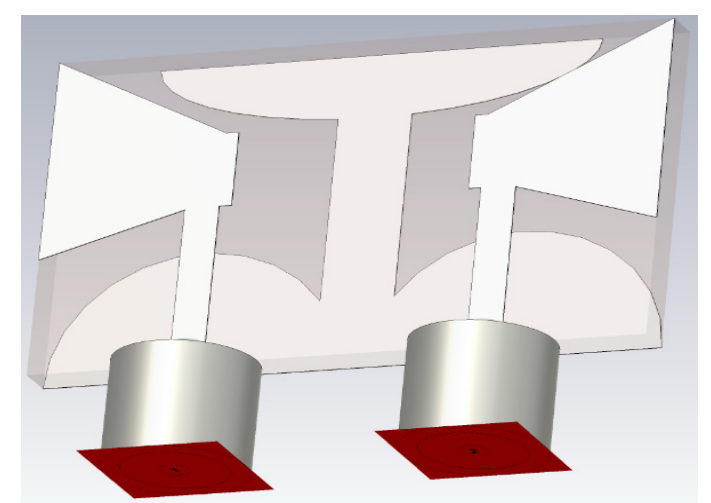

(c)

Fig. 1. Design of proposed MIMO-UWB antenna: (a) top view, (b) bottom view, and (c) perspective view.

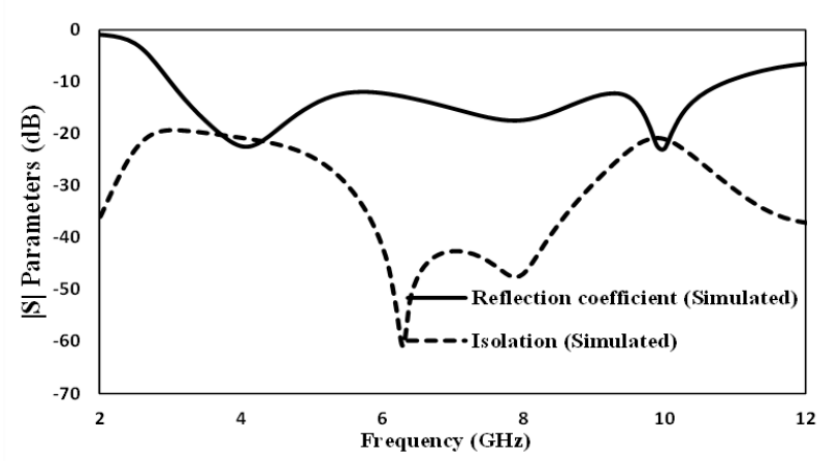

Fig. 2. Simulated $|S|$-parameters of presented MIMO antenna.
Table 2. Design dimension parameters of presented MIMO antenna

\begin{tabular}{cccc}
\hline Parameter & Value $(\mathrm{mm})$ & Parameter & Value $(\mathrm{mm})$ \\
\hline$W$ & 25 & $l_{4}$ & 9.5 \\
$L$ & 15 & $w_{r}$ & 7.7 \\
$l_{f}$ & 7.5 & $e_{1}$ & 3 \\
$w_{f}$ & 1.4 & $e_{2}$ & 18 \\
$l_{1}$ & 3.5 & $l_{s}$ & 12 \\
$l_{2}$ & 6.1 & $w_{s}$ & 3 \\
$l_{3}$ & 8 & $r_{g}$ & 6 \\
$S_{1}$ & 4.3 & $S_{6}$ & 1.1 \\
$S_{2}$ & 1.7 & $S_{7}$ & 2.5 \\
$S_{3}$ & 3 & $S_{8}$ & 1.2 \\
$S_{4}$ & 1.7 & $S_{9}$ & 3.6 \\
$S_{5}$ & 2.3 & $S_{10}$ & 1.8 \\
\hline
\end{tabular}

tances causes strong mutual coupling, and placing MIMO antennas spanning large distances necessitates increased antenna size; a decoupling stub is designed to overcome this problem. In the presented MIMO system, the T-shaped decoupling stub is designed for high isolation. The decoupling stub is evaluated in various steps, as shown in Fig. 3, and their $|S|$-parameters are illustrated in Fig. 4. As shown in Fig. 4, the mutual coupling of

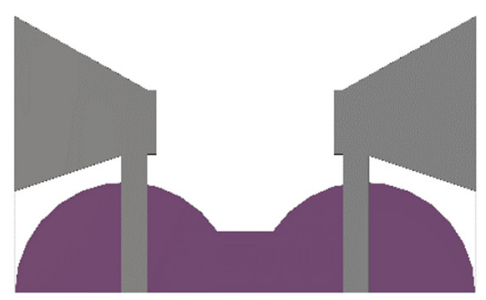

(a)

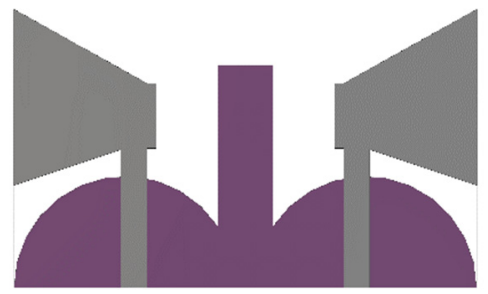

(b)

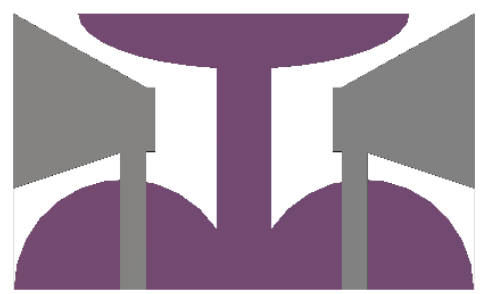

(c)

Fig. 3. Evaluation steps of decoupling stub in MIMO antenna: (a) without decoupling stub, (b) with I-shaped decoupling stub, and (c) with T-shaped decoupling stub. 


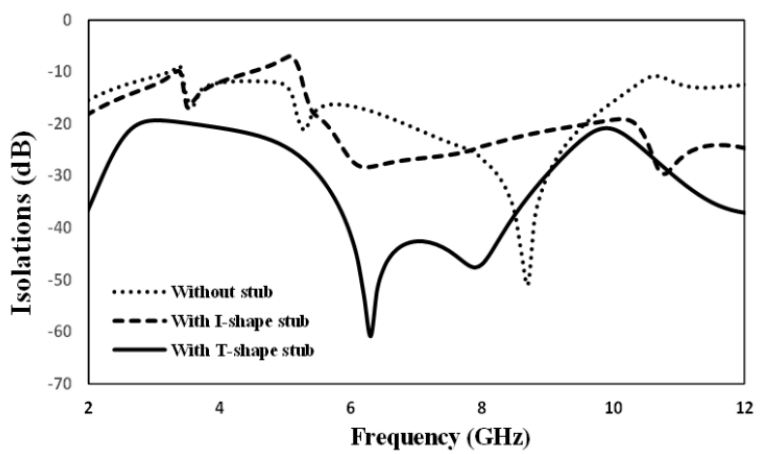

Fig. 4. Isolations of decoupling stub in presented MIMO antenna.

a MIMO antenna without a decoupling stub and an I-shaped decoupling stub are much higher than with the proposed $\mathrm{T}$ shaped decoupling stub.

Surface current distribution at $3.5 \mathrm{GHz}$ and $5.5 \mathrm{GHz}$ is shown in Fig. 5. Port1 is excited to examine surface current distribution with and without decoupling stub. In Fig. 5, without the decoupling stub, strong transmission between ports is noted; this occurred because a portion of the current was transmitted from Port1 to Port2 due to the small space between the radiating elements. The decoupling stub was added to utilize most of the current on left side of the stub and to isolate the other port.

\section{Stop Band Characteristics}

The frequency range of UWB is between $3.1 \mathrm{GHz}$ and 10.6 $\mathrm{GHz}$, but there are also some narrow bands, such as WiMAX and WLAN, that interfere with UWB communication. The slits are etched in radiating elements to stop such narrow bands. The total length of slot 1 is $13 \mathrm{~mm}$ ( slot $_{1}=S_{1}+S_{2}+S_{3}+S_{4}$ $\left.+S_{5}\right)$ and the total length of $\operatorname{slot}_{2}$ is $10.2 \mathrm{~mm}\left(\operatorname{slot}_{2}=S_{6}+S_{7}+\right.$ $S_{8}+S_{9}+S_{10}$ ); the detail values of the dimension of the slots are summarized in Table 2. The lengths of the slots are dependent on the relative permittivity of the substrate and the center frequency of the stop band. The lengths of the slots are determined from Eq. (1) [30].

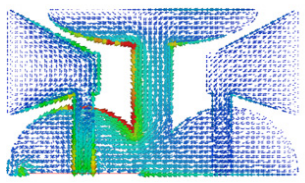

Port $1 \quad$ (a) Port 2

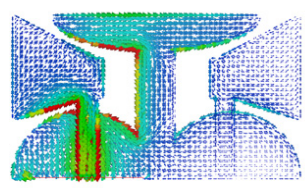

Port 1 (c) Port 2
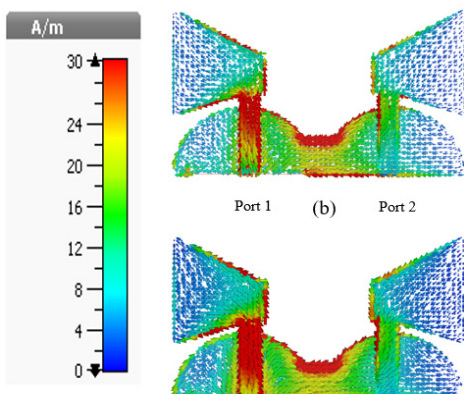

Port $1 \quad$ (b) Port 2

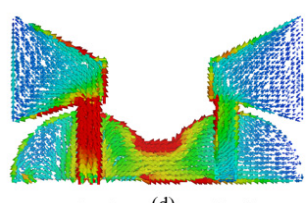

Port 1 (d) Port2
Fig. 5. Surface current distribution of MIMO antenna at: (a) 3.5 $\mathrm{GHz}$ with decoupling stub, (b) $3.5 \mathrm{GHz}$ without decoupling stub, (c) $5.5 \mathrm{GHz}$ with decoupling stub, and (d) 5.5 $\mathrm{GHz}$ without decoupling stub.

$$
L_{\text {slot } 1}=L_{\text {slot } 2}=\frac{c}{4 f_{n} \sqrt{\left(\varepsilon_{r}+1\right) / 2}}
$$

$\varepsilon_{r}$ is relative permittivity, $f_{n}$ is notch frequency and $c$ is speed of light. The evaluation steps of the notch characteristics are depicted in Fig. 6, and their $|S|$-parameters are illustrated in Fig. 7. slot $_{1}$ is used to stop the band of WiMAX and slot $t_{2}$ is used to

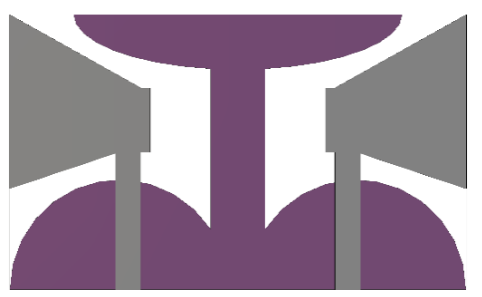

(a)

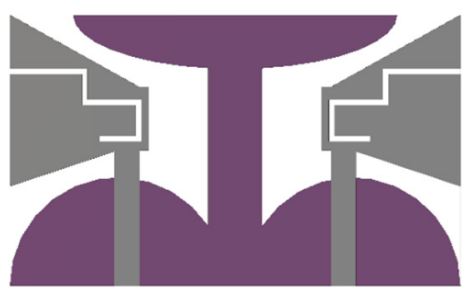

(b)

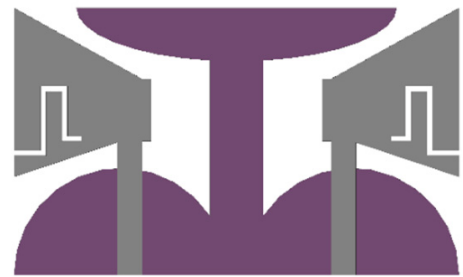

(c)

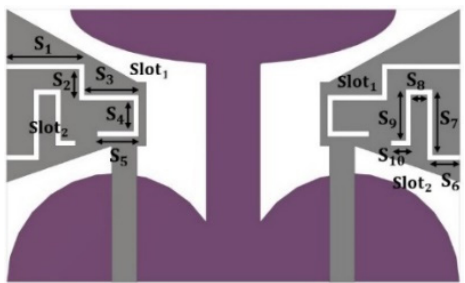

(d)

Fig. 6. Evaluation steps of notch characteristics in MIMO antenna: (a) MIMO Ant1, (b) MIMO Ant2, (c) MIMO Ant3, and (d) MIMO Ant4 (proposed design).

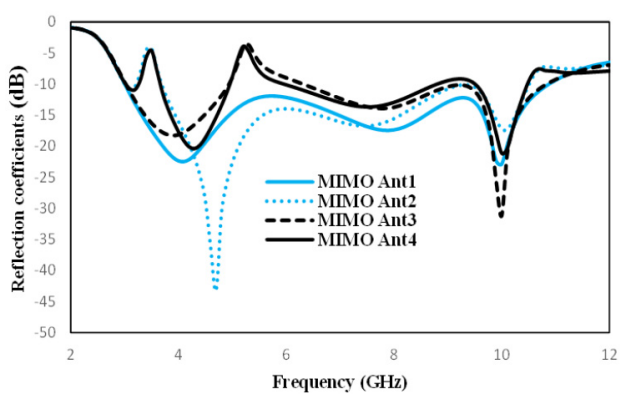

Fig. 7. Reflection coefficients of design evaluation steps of notch characteristics in proposed MIMO antenna. 
stop the band of WLAN, which are justified through Fig. 7. The MIMO Ant1 is a simple UWB antenna ranging from 3 $\mathrm{GHz}$ to $10.9 \mathrm{GHz}$, while the MIMO Ant2 stops the band of WiMAX, the MIMO Ant3 stops the band of WLAN, and the MIMO Ant4 stops both the bands; this is all shown through Fig. 7.

\section{Parametric Analysis}

The parametric analysis was accomplished by observing the variations in reflection coefficients and isolations with the variation in different parts of the antenna such as radius of the ground plane $\left(r_{g}\right)$, width of the decoupling stub $\left(w_{s}\right)$, the length and width of the radiating patch $\left(l_{3}\right)$ and the width of the feed $\left(w_{f}\right)$. The ground plane and decoupling stub have two main functions: providing impedance matching and reducing mutual coupling.

The parametric analysis of ground plane is depicted in Fig. 8. The reflection coefficient is relatively better in the entire UWB for $r_{g}=6 \mathrm{~mm}$. The mismatch losses have been increased in the 4-5 GHz frequency band and above $9 \mathrm{GHz}$ for $r_{g}=5 \mathrm{~mm}$; similarly mismatched losses occur over the entire UWB for $r_{g}=$ $7 \mathrm{~mm}$. The isolations are nearly same up to $8 \mathrm{GHz}$ but are degraded after $8 \mathrm{GHz}$ for both smaller and larger values of $r_{g}$. When the width of the decoupling stub $\left(w_{s}\right)$ varies from $2-4$ $\mathrm{mm}$, variations in the reflection coefficients and isolations are observed; this is shown in Fig. 9. Relatively better response over

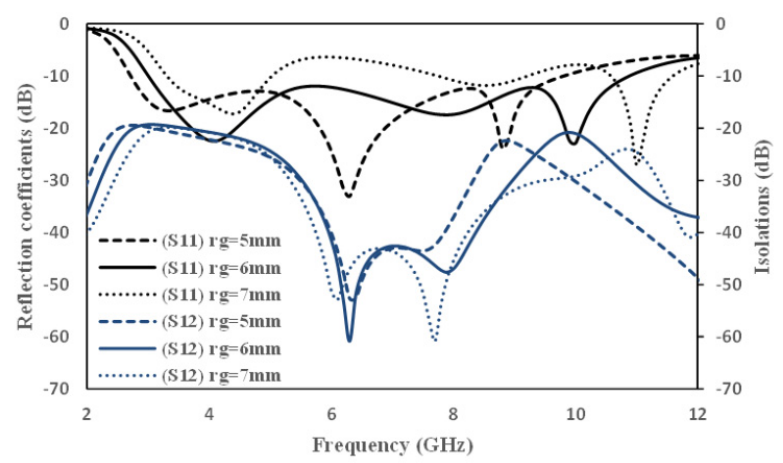

Fig. 8. Parametric analysis by varying the radius of ground plane $\left(r_{g}\right)$.

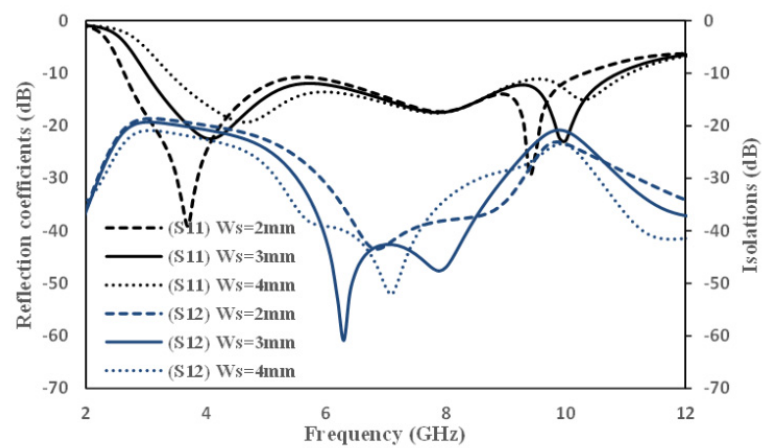

Fig. 9. Parametric analysis by varying the width of decoupling stub $\left(w_{s}\right)$. the entire UWB band is observed for $w_{s}=3 \mathrm{~mm}$. The impedance matching is poor beyond $9 \mathrm{GHz}$, and similarly, isolations are degraded beyond $6 \mathrm{GHz}$ for both smaller and larger values of $\left(w_{s}\right)$.

The parametric analysis of the radiating patch is depicted in Fig. 10. Isolation is nearly the same for all values of $l_{3}$, but reflection coefficients are drastically affected if $l_{3}$ is increased or decreased by $2 \mathrm{~mm}$. The reflection coefficient is poor between 4-8 GHz for $l_{3}=6 \mathrm{~mm}$, and there is a poor reflection coefficient beyond $7 \mathrm{GHz}$ for $l_{3}=10 \mathrm{~mm}$. The parametric analysis of the feed line is depicted in Fig. 11. The reflection coefficient is relatively better across the entire UWB for $w_{f}=1.4 \mathrm{~mm}$. Isolation is nearly the same for all values of feed width $\left(w_{f}\right)$. The mismatched losses increase across the $6-9 \mathrm{GHz}$ frequency band for $w_{f}=1.2 \mathrm{~mm}$; similarly mismatched losses occur across the 4-5 GHz for $w_{f}=1.6 \mathrm{~mm}$.

\section{RESULTS AND DISCUSSION}

The proposed MIMO antenna is printed on FR4 substrate and simulated in CST Microwave Studio. The prototype of the proposed design is depicted in Fig. 12, and the measured and simulated $|S|$-parameters are illustrated in Fig. 13. The latter figure outlines the fact that both measured and simulated reflection coefficients are less than $-10 \mathrm{~dB}$ between $3-10.9 \mathrm{GHz}$,

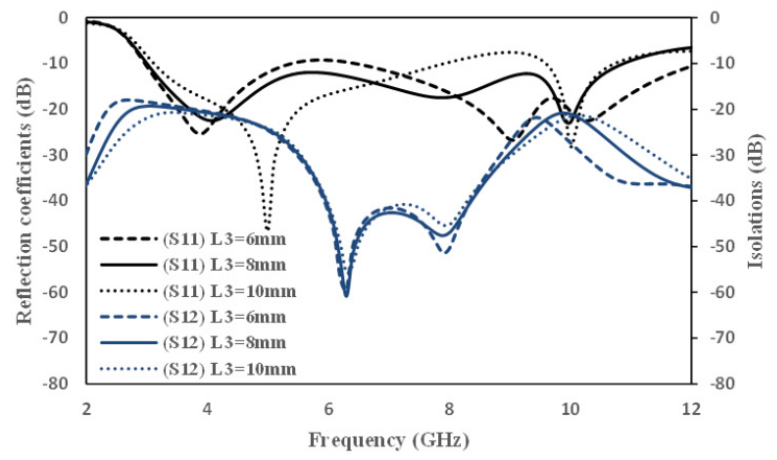

Fig. 10. Parametric analysis by varying the length and width of radiating patch $\left(l_{3}\right)$.

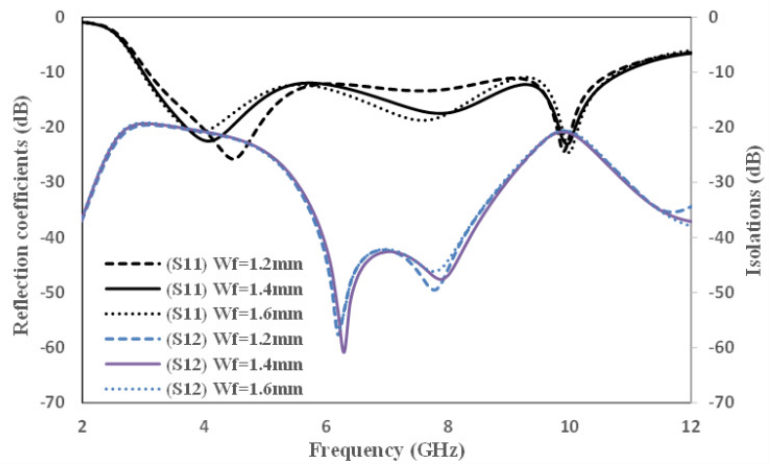

Fig. 11. Parametric analysis by varying the width of feed of radiating patch $\left(w_{f}\right)$. 


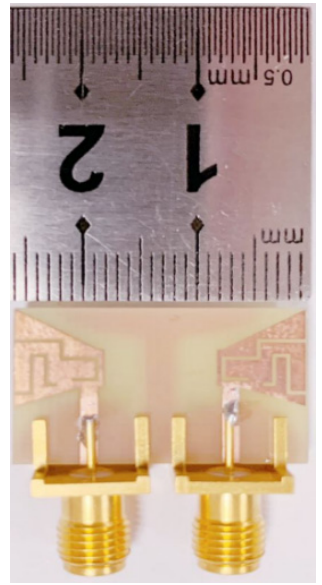

(a)

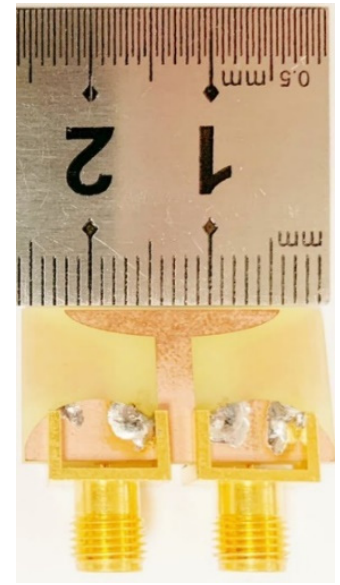

(b)
Fig. 12. Prototype of proposed MIMO-UWB antenna: (a) top view and (b) bottom view.

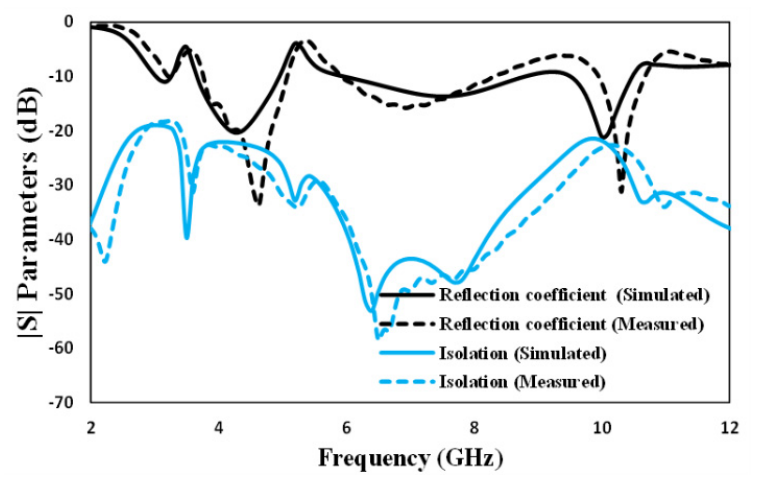

Fig. 13. Measured and simulated $|S|$-parameters of MIMO antenna.

except in the cases where the bands of WiMAX $(3.2-3.7 \mathrm{GHz})$ and WLAN (5-6 GHz) covered the entire UWB communication. Similarly, the measured and simulated isolation is greater than $20 \mathrm{~dB}$ across the entire band of UWB; both measured and simulated results are nearly same and show significant agreement. The measured and simulated E-plane $(\mathrm{YZ}, \phi=90)$ and $\mathrm{H}$-plane $(\mathrm{XZ}, \phi=0)$ radiation patterns at various frequencies are illustrated in Fig. 14. From Fig. 14, it is justified that the radiation pattern at $4.5 \mathrm{GHz}$ in both yz-Plane and xz-Plane are omni-directional radiation pattern, the radiation pattern at 7.5 $\mathrm{GHz}$ are also form nearly omni-directional radiation pattern in both yz-Plane and xz-Plane; the radiation patterns are stable in both planes on given frequencies.

Diversity performance is evaluated in terms of the ECC, diversity gains and multiplexing efficiency. Ideally, the ECC is equal to zero; practically, an ECC $<0.5$ may be acceptable. Diversity gains and ECC are calculated using Eqs. (2) and (3) [31].

$$
\begin{gathered}
\mathrm{ECC}=\frac{||_{11}^{*} S_{12}+\left.S_{21}^{*} S_{22}\right|^{2}}{\left(1-\left|S_{11}\right|^{2}-\left|S_{21}\right|^{2}\right)\left(1-\left|S_{22}\right|^{2}-\left|S_{12}\right|^{2}\right)} \\
\mathrm{DG}=10 \sqrt{1-(E C C)^{2}}
\end{gathered}
$$

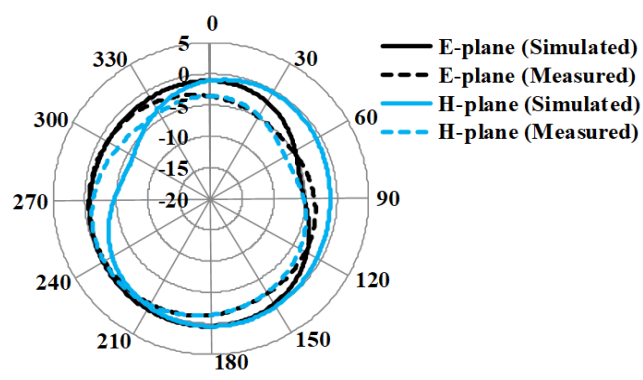

(a)

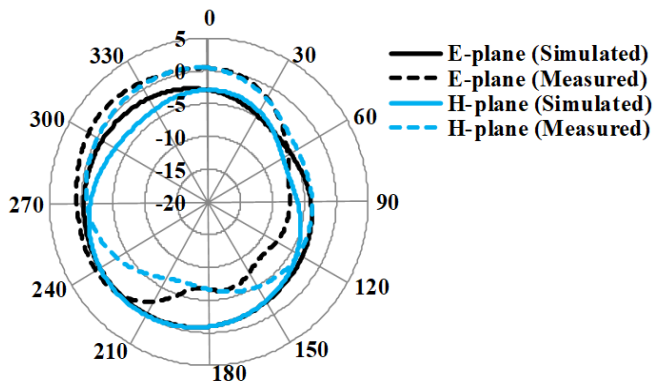

(b)

Fig. 14. Measured and simulated E-plane and $\mathrm{H}$-plane radiation patterns at: (a) $4.5 \mathrm{GHz}$ and (b) $7.5 \mathrm{GHz}$.

The measured and simulated ECC is depicted in Fig. 15. The $\mathrm{ECC}$ is 0.02 at notched frequency and almost zero at resonance frequencies. Similarly, the diversity gain is $9.9 \mathrm{~dB}$ at notched frequencies and almost equal to $10 \mathrm{~dB}$ at resonance frequencies (shown in Fig. 16). Peak gain and multiplexing efficiencies are depicted in Fig. 17; measured and simulated peak gains are

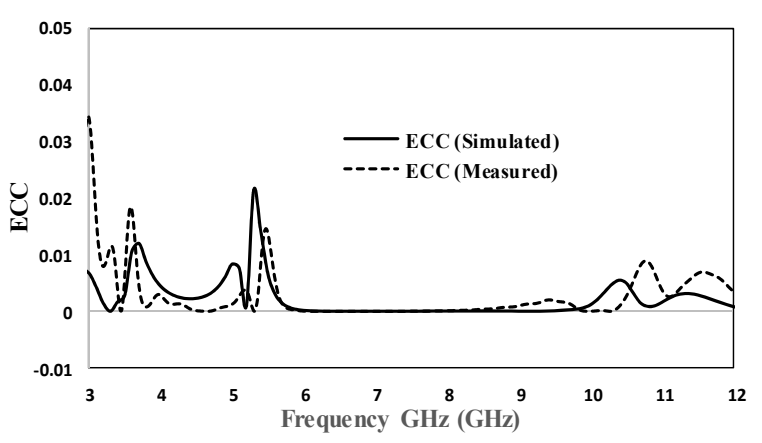

Fig. 15. Measured and simulated ECC of MIMO antenna.

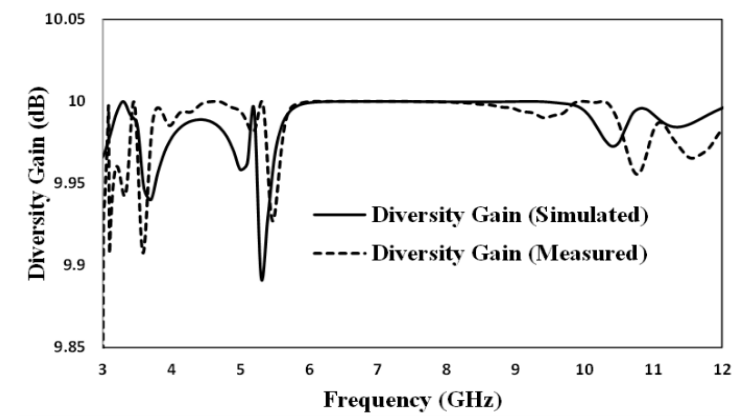

Fig. 16. Measured and simulated diversity gain of MIMO antenna. 


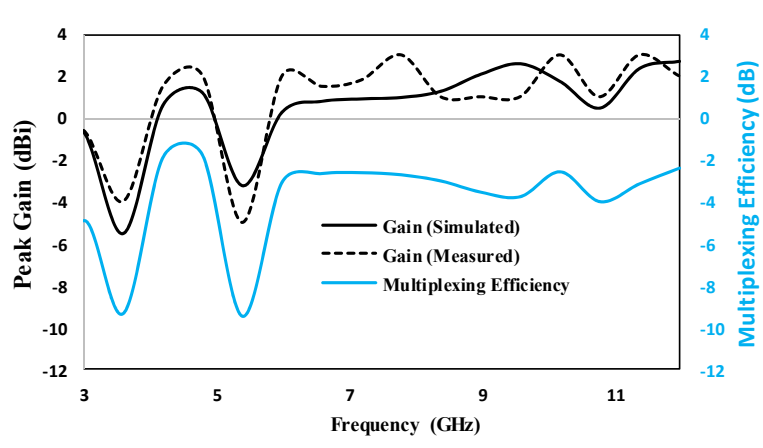

Fig. 17. Peak gain and multiplexing efficiency of MIMO antenna.

nearly same and much lower at notched frequencies when compared with other frequencies. Similarly, multiplexing efficiency was $-10 \mathrm{~dB}$ at notched frequencies and varies between $-4 \mathrm{~dB}$ and $-2 \mathrm{~dB}$ on other frequencies (shown in Fig. 17).

\section{CONCLUSION}

In this paper, a compact and new design of a MIMO system is presented. Isolation is achieved with the help of a T-shaped decoupling stub; dual bands of WiMAX (3.2-3.7 GHz) and WLAN $(5-6 \mathrm{GHz})$ are stopped with the help of slits in the radiators. The antenna is printed on FR4 substrate and optimized and simulated in CST Microwave Studio. The ECC is less than 0.02 , and the diversity gain is greater $9.9 \mathrm{~dB}$. The peak gain, ECC, multiplexing efficiency, diversity gain and radiation pattern show that the designed antenna can be used for UWBMIMO communication systems.

This work was supported in part by the Abu-Dhabi Department of Education and Knowledge (ADEK) Award for Research Excellence 2019 (Grant No. AARE19-245).

\section{REFERENCES}

[1] Federal Communications Commission, "Revision of part 15 of commission's rule regarding ultra-wideband transmission systems (FCC 02-48)," 2000 [Online]. Available: https://www.fcc.gov/document/revision-part-15-commis sions-rules-regarding-ultra-wideband-7.

[2] S. X. Ta and I. Park, "Multiband-notched UWB antenna using folded slots in the feeding structure," Journal of Electromagnetic Engineering and Science, vol. 14, no. 1, pp. 31-35, 2014.

[3] Y. Jin, J. Tak, and J. Choi, "Quadruple band-notched trapezoid UWB antenna with reduced gains in notch bands," Journal of Electromagnetic Engineering and Science, vol. 16, no. 1, pp. 35-43, 2016.
[4] K. Y. Mok, Y. C. Rhee, and J. H. Yoon, "Design of a potshaped monopole antenna with dual band notched characteristics for UWB application," Journal of Electromagnetic Engineering and Science, vol. 17, no. 1, pp. 44-49, 2017.

[5] M. I. Khattak, M. I. Khan, Z. Ullah, G. Ahmad, and A. Khan, "Hexagonal printed monopole antenna with triple stop bands for UWB applications," Mehran University Research Journal of Engineering \& Technology, vol. 38, no. 2, pp. 335-340, 2019.

[6] R. N. Tiwari, P. Singh, and B. K. Kanaujia, "A compact UWB MIMO antenna with neutralization line for WLAN/ ISM/mobile applications," International Journal of $R F$ and Microwave Computer-Aided Engineering, vol. 29, no. 11, article no. e21907, 2019. https://doi.org/10.1002/mmce. 21907

[7] W. Li, Y. Hei, P. M. Grubb, X. Shi, and R. T. Chen, "Compact inkjet-printed flexible MIMO antenna for UWB applications," IEEE Access, vol. 6, pp. 50290-50298, 2018.

[8] H. Ullah, S. U. Rahman, Q. Cao, I. Khan, and H. Ullah, "Design of SWB MIMO antenna with extremely wideband isolation," Electronics, vol. 9, no. 1, article no. 194, 2020. https://doi.org/10.3390/electronics9010194

[9] M. Irshad Khan, M. I. Khattak, S. U. Rahman, A. B. Qazi, A. A. Telba, and A. Sebak, "Design and investigation of modern UWB-MIMO antenna with optimized isolation," Micromachines, vol. 11, no 4, article no. 432, 2020. https:// doi.org/10.3390/mi11040432

[10] Y. Zhao, F. S. Zhang, L. X. Cao, and D. H. Li, "A compact dual band-notched MIMO diversity antenna for UWB wireless applications," Progress In Electromagnetics Research C, vol. 89, pp. 161-169, 2019.

[11] L. Liu, S. W. Cheung, and T. I. Yuk, "Compact MIMO antenna for portable UWB applications with band-notched characteristic," IEEE Transactions on Antennas and Propagation, vol. 63, no. 5, pp. 1917-1924, 2015.

[12] W. T. Li, Y. Q. Hei, H. Subbaraman, X. W. Shi, and R. T. Chen, "Novel printed filtenna with dual notches and good out-of-band characteristics for UWB-MIMO applications," IEEE Microwave and Wireless Components Letters, vol. 26, no. 10, pp. 765-767, 2016.

[13] N. Jaglan, S. D. Gupta, E. Thakur, D. Kumar, B. K. Kanaujia, and S. Srivastava, "Triple band notched mushroom and uniplanar EBG structures based UWB MIMO/ Diversity antenna with enhanced wide band isolation," AEU-International Journal of Electronics and Communications, vol. 90, pp. 36-44, 2018.

[14] M. A. U. Haq and S. Koziel, "Ground plane alterations for design of high-isolation compact wideband MIMO antenna," IEEE Access, vol. 6, pp. 48978-48983, 2018.

[15] Z. Li, C. Yin, and X. Zhu, "Compact UWB MIMO Vi- 
valdi antenna with dual band-notched characteristics," IEEE Access, vol. 7, pp. 38696-38701, 2019.

[16] A. Kumar, A. Q. Ansari, B. K. Kanaujia, J. Kishor, and S. Kumar, "An ultra-compact two-port UWB-MIMO antenna with dual band-notched characteristics," $A E U$ International Journal of Electronics and Communications, vol. 114, article no. 152997, 2020. https://doi.org/10.10 16/j.aeue.2019.152997

[17] H. T. Chattha, F. Latif, F. A. Tahir, M. U. Khan, and X. Yang, "Small-sized UWB MIMO antenna with band rejection capability," IEEE Access, vol. 7, pp. 121816-121824, 2019.

[18] K. V. Babu and B. Anuradha, "Design of MIMO antenna to interference inherent for ultra wide band systems using defected ground structure," Microwave and Optical Technology Letters, vol. 61, no. 12, pp. 2698-2708, 2019.

[19] R. Mathur and S. Dwari, "Compact planar reconfigurable UWB-MIMO antenna with on-demand worldwide interoperability for microwave access/wireless local area network rejection," IET Microwaves, Antennas \& Propagation, vol. 13, no. 10, pp. 1684-1689, 2019.

[20] T. Dabas, D. Gangwar, B. K. Kanaujia, and A. K. Gautam, "Mutual coupling reduction between elements of UWB MIMO antenna using small size uniplanar EBG exhibiting multiple stop bands," AEU-International Journal of Electronics and Communications, vol. 93, pp. 32-38, 2018.

[21] M. I. Khan and M. I. Khattak, "Designing and analyzing a modern MIMO-UWB antenna with a novel stub for stop band characteristics and reduced mutual coupling," Microwave and Optical Technology Letters, vol. 62, no. 10, pp. 3209-3214, 2020.

[22] Y. K. Lee, H. I. Chung, and J. H. Choi, "Improving the isolation of MIMO antennas using split ring resonators," Journal of Electromagnetic Engineering and Science, vol. 10, no. 4, pp. 303-308, 2010.

[23] S. Lim, W. C. Choi, and Y. J. Yoon, "Miniaturized radio frequency choke using modified stubs for high isolation in MIMO systems," Journal of Electromagnetic Engineering and Science, vol. 15, no. 4, pp. 219-223, 2015.

[24] D. Kwon, S. J. Lee, J. W. Kim, B. Ahn, J. W. Yu, and W. S. Lee, "An eight-element compact low-profile planar MIMO antenna using LC resonance with high isolation," Journal of Electromagnetic Engineering and Science, vol. 16, no. 3, pp. 194-197, 2016.

[25] S. H. Kim and J. Y. Chung, "Analysis of the envelope correlation coefficient of MIMO antennas connected with suspended lines," Journal of Electromagnetic Engineering and Science, vol. 20, no. 2, pp. 83-90, 2020.

[26] S. Kumar, G. H. Lee, D. H. Kim, W. Mohyuddin, H. C. Choi, and K. W. Kim, "Multiple-input-multiple-output/ diversity antenna with dual band-notched characteristics for ultra-wideband applications," Microwave and Optical Technology Letters, vol. 62, no. 1, pp. 336-345, 2020.

[27] S. P. Biswal and S. Das, "A low-profile dual port UWB$\mathrm{MIMO}$ /diversity antenna with band rejection ability," International Journal of $R F$ and Microwave ComputerAided Engineering, vol. 28, no. 1, article no. e21159, 2018. https://doi.org/10.1002/mmce.21159

[28] L. Kang, H. Li, X. Wang, and X. Shi, "Compact offset microstrip-fed MIMO antenna for band-notched UWB applications," IEEE Antennas and Wireless Propagation Letters, vol. 14, pp. 1754-1757, 2015.

[29] S. Rajkumar, A. Anto Amala, and K. T. Selvan, "Isolation improvement of UWB MIMO antenna utilising molecule fractal structure," Electronics Letters, vol. 55, no. 10, pp. 576-579, 2019.

[30] Q. X. Chu and Y. Y. Yang, "A compact ultrawideband antenna with 3.4/5.5 GHz dual band-notched characteristics," IEEE Transactions on Antennas and Propagation, vol. 56, no. 12, pp. 3637-3644, 2008.

[31] S. Blanch, J. Romeu, and I. Corbella, "Exact representation of antenna system diversity performance from input parameter description," Electronics Letters, vol. 39, no. 9, pp. 705-707, 2003. 


\section{Muhammad Irshad Khan}

received a B.Sc. (Hons.) degree in electrical electronic engineering from the Comsats Institute of Information Technology Abbottabad, Pakistan, and an M.S. degree in electrical engineering from the Capital University of Science and Technology, Islamabad, Pakistan, in 2016. He completed a Ph.D. in electrical engineering under the supervision of Dr. Khattak from the University of Engineering and Technology, Peshawar, Pakistan. His research interests include microwave and RF circuit design, UWB antenna design and analysis, MIMO antennas, beamsteering antennas and reconfigurable antenna design.

\section{Muath Al-Hasan}

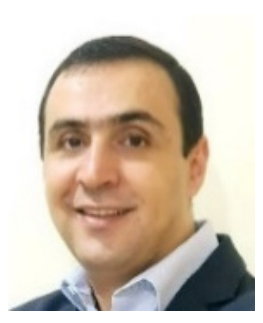

received a B.A.Sc. degree in electrical engineering from the Jordan University of Science and Technology, Jordan, in 2005, an M.A.Sc. in wireless communications from Yarmouk University, Jordan, in 2008, and a $\mathrm{Ph} . \mathrm{D}$. in telecommunication engineering from Institut National de la Recherche Scientifique (INRS), Université du Québec, Canada, 2015. From 2013 to 2014, he worked with Planets Inc., in California, USA. In May 2015, he joined Concordia University, Canada, on a postdoctoral fellowship. He is currently an assistant professor with Al Ain University, United Arab Emirates. His current research interests include antenna design at millimeter-wave and terahertz, channel measurements in MIMO systems, as well as and machine learning and artificial intelligence in antenna design.

\section{Muhammad Irfan Khattak}

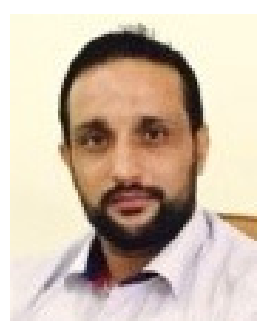

received a B.Sc. degree in electrical engineering from the University of Engineering and Technology, Peshawar, in 2004, and a Ph.D. from Loughborough University, UK, in 2010. After doing his Ph.D., he was appointed Chairman of the Electrical Engi-neering Department, UET Bannu Campus, for five years and took care of the academic and research activities at the department. Later, in 2016, he was appointed Campus Coordinator of the UET Kohat Campus and took administrative control of the campus. He is currently working as an associate professor with the Department of Electrical Engineering, University of Engineering and Technology. He is also heading a research group focused on microwave and antenna research, where he is supervising postgrad students working on the latest trends in antenna technology (e.g., 5G and graphene nanoantennas for terahertz, optoelectronic and plasmonic app-lications, etc.). His research interests involve antenna design, on-body communications, anechoic chamber characterization, as well as speech pro-cessing and enhancement. Aside from his research activities, he is a certified OBE expert with the Pakistan Engineering Council for organizing OBE-based accreditation visits. 